(1) rapidly moving pairs for which orbits have been computed or will be computed within a few decades ; (2) pairs which, though not moving rapidly, nevertheless deserve an observation in the present decade, either because they are known to have a slow motion or because they may be neglected pairs.

Section C, Photoheliographic Observations, gives the positions and areas of sunspots and faculæ for each day in the year 1936. Photographs from three observatories were used. Those obtained at the Royal Observatory, Greenwich, were taken with the Dallemeyer photoheliograph of 4 in. aperture, usually stopped down to 2.9 in., and, in a few cases, with the Thompson photoheliograph of $9 \mathrm{in}$. aperture. The diameter of the sun's image at the secondary focus in both instruments is $7 \frac{1}{2}$.in. at the earth's mean distance. The photographs from the Cape Observatory were taken with a Dallmeyer photoheliograph giving an image of the sun about $7 \frac{1}{2}$ in. in diameter. Those obtained at Kodaikánal were taken with a Cooke photovisual object-glass of 6 in. aperture, the image of the sun being on nearly the same scale. This section also gives a general catalogue of groups of sunspots for 1936 and 'ledgers' of the areas and heliographic positions of groups of sunspots for 1936 .

Sections D and E, Magnetio and Meteorological Observations, give a full description of the buildings and equipment of the magnetic station at Abinger and also of the results of the magnetic observations, followed by a corresponding description of the meteorological apparatus and the results of the observations.

\title{
CONCRETE IN SEA WATER
}

\begin{abstract}
$7 \mathrm{HE}$ current issue of the Dock and Harbour Authority contains the reproduction from the Proceedings of the American Society of Civil Engineers of a paper by Homer M. Radley in which the author gave a statement of the conclusions he has reached as a result of extended observation of concrete marine structures along the Pacific coast of the United States and Canada. Contrary to the widely held view that decomposition of concrete in sea water must necessarily occur as a result of the chemical action of sulphate of magnesium, he states that, over a long period no evidence of any attack of this nature was found, and he holds that such deterioration as occurs is due to other causes.

Arguing from the characteristic form and manifestation of attack by magnesium sulphate as advanced by Vicat, he concludes that, if this occurred in the manner described, exposure to full sea-water action for a period of twelve or fifteen years should produce distinct evidence of porosity or disintegration. His investigation showed, on the contrary, that concretes made with many brands of Portland cement
\end{abstract}

continue after fifteen or more years of service to exhibit the original wood-grain and other marks of the shuttering used in construction. He points to several other causes of disintegration and disruption - the rise and fall of the tides and the alternate wetting and drying of the concrete surface, mechanical blows and abrasion from flotsam and drift, and the action of storm waves and the grinding of the boulders which they toss about. Deficiencies in the quality and structure of the concrete are responsible for the most characteristic forms of deterioration, weak concrete being readily abraded, honeycombed areas becoming cavitated, laitance seams giving rise to extended voids and so on. In these respects he finds little to choose between fresh water and salt. water, and contends that the same qualities which give resistance in the one are good in the other. Associated with salt water there is, however, the scaling and disruption which arise from the crystallization of salt in the exposed upper parts. These several aspects of deterioration are discussed in considerable detail, and many photographs illustrate the different types noted.

\section{THE IMPERIAL CANCER RESEARCH FUND}

\section{By DR. E. BOYLAND}

$\mathrm{T}$ HE thirty-eighth annual report of the Imperial Cancer Research Fund was presented to the general meeting of governors in April. New work on the nature and cause of cancer has been carried out in the Fund's laboratories at Mill Hill. In addition to this normal work, Miss Ida Mann and Dr. B. D. Pullinger have carried out experiments on the effect of ascorbic acid in mustard gas burns of the eye, and on other problems for the Ministry of Supply. Several members of the staff have been absent on war service and, although the volume of research is perhaps not so large as in normal years, work of interest and real value has been accomplished.

Histology is still an important and essential branch of cancer research. Without the microscope it would often be difficult or impossible to determine whether tumours were malignant or not. Dr. L. Foulds has written a critical review on the histology of tumours ${ }^{1}$, a field in which workers in the Imperial Cancer Research Fund laboratories have made important contributions in the past.

Dr. B. D. Pullinger has extended her investigation on the specific response which is given by mouse skin to carcinogenic substances. With the carcinogenic $5: 9: 10$-trimethyl-1:2-benzanthracene small amounts produce the response while larger amounts destroy the epithelium without producing the characteristic reactions. This result fits in with the finding of Prof. E. L. Kennaway and Prof. J. W. Cook that this substance is a more effective carcinogenic agent in dilute than in strong solutions.

Mr. H. G. Crabtree has continued his investigations 